\title{
Inhibition of adenosine A1 receptors abolished the nutritional ketosis-evoked delay in the onset of isoflurane-induced anesthesia in Wistar Albino Glaxo Rijswijk rats
}

\author{
Zsolt Kovács ${ }^{1}$, Brigitta Brunner ${ }^{1,2}$, Dominic P. D'Agostino ${ }^{3,4}$ and Csilla Ari ${ }^{5^{*}}$ (i)
}

\begin{abstract}
Background: It has been demonstrated that administration of exogenous ketone supplement ketone salt (KS) and ketone ester (KE) increased blood ketone level and delayed the onset of isoflurane-induced anesthesia in different rodent models, such as Wistar Albino Glaxo Rijswijk (WAG/Rij) rats. The modulatory effect of adenosinergic system may have a role in the ketone supplementation-evoked effects on isoflurane-generated anesthesia. Thus, we investigated whether adenosine receptor antagonists can modulate the effect of exogenous ketone supplements on the onset of akinesia induced by isoflurane.
\end{abstract}

Methods: To investigate the effect of exogenous ketone supplements on anesthetic induction we used ketone supplement KE, KS, KEKS (1:1 mix of KE and KS), KSMCT and KEMCT (1:1 mix of KS and KE with medium chain triglyceride/MCT oil, respectively) in WAG/Rij rats. Animals were fed with standard diet (SD), which was supplemented by oral gavage of different ketone supplements (2.5 g/kg/day) for 1 week. After 7 days, isoflurane (3\%) was administered for 5 min and the time until onset of isoflurane-induced anesthesia (time until immobility; light phase of anesthesia: loss of consciousness without movement) was measured. Changes in levels of blood $\beta$-hydroxybutyrate ( $\beta \mathrm{HB})$, blood glucose and body weight of animals were also recorded. To investigate the putative effects of adenosine receptors on ketone supplements-evoked influence on isoflurane-induced anesthesia we used a specific adenosine A1 receptor antagonist DPCPX (intraperitoneally/i.p. 0.2 mg/kg) and a selective adenosine A2A receptor antagonist SCH 58261 (i.p. $0.5 \mathrm{mg} / \mathrm{kg}$ ) alone as well as in combination with KEKS.

Results: Significant increases were demonstrated in both blood $\beta H B$ levels and the number of seconds required before isoflurane-induced anesthesia (immobility) after the final treatment by all exogenous ketone supplements. Moreover, this effect of exogenous ketone supplements positively correlated with blood $\beta \mathrm{HB}$ levels. It was also demonstrated that DPCPX completely abolished the effect of KEKS on isoflurane-induced anesthesia (time until immobility), but not SCH 58261.

Conclusions: These findings strengthen our previous suggestion that exogenous ketone supplements may modulate the isoflurane-induced onset of anesthesia (immobility), likely through A1Rs.

Keywords: Isoflurane, Anesthesia, Exogenous ketone supplements, Ketosis, Adenosine receptors

\footnotetext{
* Correspondence: csari2000@yahoo.com

${ }^{5}$ Department of Psychology, Hyperbaric Neuroscience Research Laboratory,

University of South Florida, 4202 E. Fowler Ave, PCD 3127, Tampa, FL 33620,

USA

Full list of author information is available at the end of the article
}

(c) The Author(s). 2020 Open Access This article is distributed under the terms of the Creative Commons Attribution 4.0 International License (http://creativecommons.org/licenses/by/4.0/), which permits unrestricted use, distribution, and reproduction in any medium, provided you give appropriate credit to the original author(s) and the source, provide a link to the Creative Commons license, and indicate if changes were made. The Creative Commons Public Domain Dedication waiver (http://creativecommons.org/publicdomain/zero/1.0/) applies to the data made available in this article, unless otherwise stated. 


\section{Background}

It has been demonstrated that exogenous ketone (ketogenic) supplements, such as ketone ester (KE), not only increase the level of ketone bodies (e.g., $\beta$-hydroxybutyrate/ $\beta \mathrm{HB})[1-5]$, but also maintain blood levels of ketone bodies in both animals and humans [2, 3, 6]. Ketone bodies, such as $\beta \mathrm{HB}$, enter into the brain through blood-brain barrier and provide fuel to brain cells $[7,8]$ improving cell energy metabolism (e.g., enhance mitochondrial ATP synthesis) [9]. Moreover, ketone supplement-induced ketosis can suppress neuronal excitability $[7,10,11]$, modulate functions of ion channels and neurotransmitter systems (e.g., increase GABA and adenosine levels) [7, 12-14] and influence inflammatory processes (e.g., decrease the concentration and expression of proinflammatory cytokines) [15]. It was suggested that these effects of ketosis may have therapeutic potential in the treatment of several central nervous system (CNS) diseases, such as Alzheimer's disease, Parkinson's disease, epilepsy and psychiatric disorders (e.g., anxiety, schizophrenia and depression) $[1,3,8,16]$. It was also demonstrated that exogenous ketone supplements, such as $\mathrm{KE}$ and ketone salt (KS) are relatively well-tolerated without (or with minimal) adverse effects $[1,2,6,16,17]$. However, exact mechanism(s) of action of exogenous ketone supplement-generated ketosis on CNS diseases and other pathophysiological and physiological processes are largely unknown.

It was suggested that ketosis may modulate sleep and sleep-like effects [18-22]. Indeed, it has been demonstrated recently that nutritional ketosis (evoked by exogenous ketone supplements, such as KE) delayed the onset of inhalational anesthetics isoflurane (1-chloro-2,2, 2-trifluoroethyl difluoromethyl ether)- induced anesthesia (immobility) [23] (light phase of anesthesia: loss of consciousness without movement, which was defined as immobility') [24]. Nevertheless, mechanism of action of ketosis-induced changes in isoflurane-evoked anesthesia remains unknown. It was suggested that changes, for example, in functioning of different ion channels (e.g., $\mathrm{K}_{\mathrm{ATP}}$ channels), neurotransmitter systems (e.g., GABAergic and adenosinergic system) and mitochondria (e.g., mitochondrial respiration) may have a role in ketone supplementevoked effects on isoflurane-generated anesthesia [19, 23, 25-27]. However, it has also been demonstrated that ketosis (evoked by exogenous ketone supplements) [1, 2, 4, 5] may increase adenosine level in the brain [14] and adenosine may have a role not only in the sleep [28], but also the generation of sleep-like effects $[29,30]$. Therefore, in this study, we examined the effect of ketone supplement $\mathrm{KE}, \mathrm{KS}$ and their mix (KEKS), as well as mix of KS and KE with medium chain triglyceride (MCT) oil (KSMCT and KEMCT, respectively) on isoflurane-induced onset of anesthesia (latency to immobility). Animals (Wistar Albino Glaxo Rijswijk/WAG/Rij rats) were fed with standard diet (SD) and were gavaged with different ketogenic supplements for 1 week $(2.5 \mathrm{~g} / \mathrm{kg} /$ day $)$. After the last supplement gavage we recorded the time until onset of immobility (under 3\% isoflurane). In the second part of the study, the potential role of adenosine receptors in the nutritional ketosis-evoked effects on isoflurane-induced onset of anesthesia (immobility) was investigated. We used a specific adenosine A1 receptor (A1R) antagonist DPCPX (1,3-dipropyl-8-cyclopentylxanthine) (intraperitoneally/i.p. $0.2 \mathrm{mg} / \mathrm{kg}$ ) and a selective adenosine A2A receptor (A2AR) antagonist SCH 58261 (7-(2-phenylethyl)-5-amino-2-(2-furyl)-pyrazolo-[4,3-e]-1,2,4-triazolo[1,5-c]pyrimidine) (i.p. $0.5 \mathrm{mg} / \mathrm{kg}$ ) alone as well as in combination with KEKS ( $2.5 \mathrm{~g} / \mathrm{kg} /$ day, gavage).

This study is the continuation of our previous study on genetically absence epileptic WAG/Rij rat strain (a wellinvestigated model of human absence epilepsy) [31], in which it was demonstrated that exogenous ketone supplements (such as KE) delayed the onset of isofluraneinduced anesthesia (increased the time required before immobility) [23]. These effects may be clinically relevant because administration of exogenous ketone supplementsinduced ketosis are more and more widely used as a metabolic therapy in the treatment of different CNS diseases, such as epilepsy or other seizure disorders [2, 8, 32-35]. Consequently, in order to implement a safe and successful anesthesia, potential effects of ketosis on the latency to anesthesia might need to be considered when epileptic patients are undergoing anesthetic procedures. For this reason, this study was performed on WAG/Rij rats, to better understand the ketone supplement-evoked effects on isoflurane-generated onset of anesthesia and its mechanism of action under epileptic condition.

In this study we hypothesized that adenosine receptor inhibition may modulate the exogenous ketone supplement-evoked delay in the latency to onset of immobility.

\section{Methods \\ Animals}

Animal treatments were carried out according to the Hungarian Act of Animal Care and Experimentation (1998, XXVIII, section 243), European Communities Council Directive 24 November 1986 (86/609/EEC) and EU Directive 2010/63/EU to use and treat animals in experimental laboratories. The experimental design was approved by the Animal Care and Experimentation Committee of the Eötvös Loránd University (Savaria University Centre) and National Scientific Ethical Committee on Animal Experimentation (Hungary) under license number VA/ÉBNTF02/85-8/2016.

Male WAG/Rij rats $(n=80 ; 6$ months old, $315-332$ g; breeding colony of WAG/Rij rats at Eötvös Loránd University, Savaria University Centre, Szombathely, 
Hungary) were kept in groups of 3-4 under standard laboratory conditions (12:12 h light-dark cycle, light was on from 08.00 AM to 08.00 PM; free access to food and water; air-conditioned room at $22 \pm 2{ }^{\circ} \mathrm{C}$ ). Rats were fed with standard rodent chow diet (SD), and received oral (intragastric) gavage of either water (control) or different ketone supplements (KE, KS, KSMCT, KEKS or KEMCT). The animals were euthanized after the last treatment and data collection by using isoflurane. All efforts were made to minimize pain and suffering and to reduce the number of animals used.

\section{Treatment groups and detection of immobility}

Both KE (1,3-butanediol - acetoacetate diester) and $\mathrm{KS}\left(\mathrm{Na}^{+} /\right.$ $\mathrm{K}^{+}-\beta \mathrm{HB}$ mineral salt) were developed by D'Agostino et al. [2] (University of South Florida/USF, United States) in collaboration with Savind, Inc. (Urbana, IL, United States). Ketone salt was mixed into a $50 \%$ solution $(375 \mathrm{mg} / \mathrm{g}$ pure $\beta \mathrm{HB}$ and $125 \mathrm{mg} / \mathrm{g} \mathrm{of} \mathrm{Na}^{+} / \mathrm{K}^{+}$in a 1:1 ratio). Medium chain triglyceride (MCT) oil (pharmaceutical grade; approximately $60 \%$ caprylic triglyceride and $40 \%$ capric triglyceride) was purchased from Now Foods (Bloomingdale, IL, United States).

We demonstrated previously the tolerability and effectiveness of exogenous ketone supplements KE, KS, KSMCT (mix of KS and MCT oil in a 1:1 ratio), KEKS (mix of KE and KS in a 1:1 ratio) and KEMCT (mix of KE and MCT oil in a 1:1 ratio) given by intragastric gavage (ad libitum access to normal rat chow $+2.5 \mathrm{~g} / \mathrm{kg}$ body weight supplements by gavage once/day in WAG/Rij rats) [1, 4, 32, 36]. Mix of ketone supplements (KSMCT, KEKS, and KEMCT) was carried out at the Eötvös Loránd University (Savaria University Centre, HUNGARY). These types and dose of ketone supplements introduced by oral gavage once per day for 7 days effectively induced and maintained ketosis in our previous studies $[1,32,36]$ without causing side effects. Therefore, in the first phase of this study, $2.5 \mathrm{~g} / \mathrm{kg} /$ day dosage of ketone supplements (KE, KS, KSMCT, KEKS and KEMCT) was administered daily by gavage for 7 days. In the second phase of the study, to investigate the putative adenosinergic mechanism of action of ketone supplements on isoflurane-evoked anesthesia (latency to immobility), we also used a specific A1R antagonist DPCPX and a selective A2AR antagonist SCH 58261, which drugs were dissolved in 10\% dimethyl sulfoxide (DMSO). All drugs were purchased from SigmaAldrich Inc. (Hungary, Budapest). In order to minimize the putative adverse effects of drugs and to induce antagonism of A1Rs and A2ARs without changes in absence epileptic activity we used previously tested and effective i.p. dose of DPCPX and SCH $58261(0.2 \mathrm{mg} / \mathrm{kg}$ DPCPX and $0.5 \mathrm{mg} / \mathrm{kg}$ SCH 58261) alone as well as in combination with KEKS (2.5 $\mathrm{g} / \mathrm{kg} /$ day, gavage) [32, 37, 38]. Moreover, it was demonstrated previously that $10 \%$ of DMSO alone has no effect on absence epileptic activity (spike-wave discharges, SWDs) in WAG/Rij rats [39] and on sleep architecture in rats [40].
Oral gavage is a relatively stressful administration method, which may affect the sensitivity of animals to anesthetics [41]. Thus, to familiarize the animals to the methods, the 7 days gavage treatment was preceded by i.p. injection of $0.5 \mathrm{ml}$ saline $/ 100 \mathrm{~g}$ body weight and (30 min later) by water gavage for 5 days (adaptation period). Following adaptation period, rats were randomly assigned into 10 groups with 8 animals in each group. All of the rats were injected i.p. by $0.5 \mathrm{ml}$ saline $/ 100 \mathrm{~g}$ body weight/every day $30 \mathrm{~min}$ before gavage. After the i.p. injection, water $(2.5 \mathrm{~g} / \mathrm{kg}$ body weight/day, group 1; $\mathrm{SD}$, control group) or exogenous ketone supplements (KE, KS, KSMCT, KEKS or KEMCT: $2.5 \mathrm{~g} / \mathrm{kg}$ body weight/day; group 2-6, respectively) were administered by gavage for 7 days. One hour after the 7 th treatments, anesthesia was induced in an air tight anesthesia chamber with isoflurane (3\% isoflurane gas mixed with air for $5 \mathrm{~min}$ ). Time from chamber closure until immobility (loss of consciousness without movement) was measured and analyzed by a blinded observer similar to previously [23]. To test the putative effect of DPCPX and $\mathrm{SCH}$ 58261 alone on isoflurane-induced anesthesia (latency to immobility), animals were i.p. injected and gavaged similar to group 1, but on the 7th treatment (water gavage) day, i.p. injections contained $0.2 \mathrm{mg} / \mathrm{kg}$ DPCPX (group 7) or $0.5 \mathrm{mg} / \mathrm{kg} \mathrm{SCH} 58261$ (group 8) in $0.5 \mathrm{ml} 10 \%$ DMSO solution/100 g body weight. Based on results on group 2-6, the most effective ketone supplement (KEKS) was chosen for investigation of the putative mechanism of action. Therefore, animals (group 9 and group 10) were i.p. injected by saline and gavaged for 7 days by KEKS similar to described above, but on the 7th treatment (KEKS gavage) day, the i.p. injections contained $0.2 \mathrm{mg} / \mathrm{kg}$ DPCPX (group 9) or $0.5 \mathrm{mg} / \mathrm{kg} \mathrm{SCH} 58261$ (group 10) in $0.5 \mathrm{ml} 10 \%$ DMSO solution $/ 100 \mathrm{~g}$ body weight. After administration of i.p. DPCPX (group 7) and SCH 58261 (group 8) alone as well as combined administration of KEKS with i.p. DPCPX (group 9) or SCH 58261 (group 10), anesthesia was induced and immobility was measured similar to group 1-6 on the 7th treatment days.

Each rat was used only in one of the treatment groups and was euthanized with isoflurane after the 7th treatment and data collection.

\section{Measurement of blood $\beta \mathrm{HB}$ and glucose levels as well as body weight}

Blood was taken from the tail vein of rats. $\beta \mathrm{HB}$ levels were measured by a commercially available glucose and ketone monitoring system (Precision Xtra ${ }^{\mathrm{mm}}$, Abbott Laboratories, Abbott Park, IL, USA) [1, 23, 32]. Total blood ketone levels ( $\mathrm{D}-\beta \mathrm{HB}+\mathrm{L}-\beta \mathrm{HB}+$ acetoacetate + acetone) would be higher than we measured because this instrument only measures blood levels of D- $\beta \mathrm{HB}$. Baseline 
$\beta \mathrm{HB}$ and glucose levels were measured on the last (5th) day of the adaptation period (group 1-6). Levels of $\beta \mathrm{HB}$ and glucose were measured again after the last (7th) day of water (group 1, control) and ketone supplementation (gavage; group 2-6) on awake animals, approximately $10 \mathrm{~min}$ after the detection of isoflurane-induced anesthesia (immobility) [23].

Body weight of rats were measured before (on last/5th day of the adaptation period) and after (on last/7th day of gavage) the treatments (group 1-6).

\section{Statistics}

All data were presented as the mean \pm standard error of the mean (S.E.M.). We compared the latency of isofluraneinduced anesthesia (immobility) in control group (SD; group 1; gavaged by water for 7 days) and treated groups (gavaged by different exogenous ketone supplements for 7 days: group 2-6; i.p. injected by DPCPX or SCH 58261 alone on 7th treatment days: group 7, and group 8; administration of KEKS in combination with i.p. DPCPX or SCH 58261 on 7th treatment days: group 9, and group 10). Moreover, baseline (last/5th day of the adaptation period; group 1-6), control (SD; group 1; 7th day) and ketone supplements-induced (group 2-6; 7th day) blood glucose and $\beta \mathrm{HB}$ levels as well as body weight (before treatment and after treatment: group 16) were also compared. Data analysis was performed using GraphPad Prism version 6.0a using a two-way ANOVA with Tukey's multiple comparisons test. Pearson correlation was calculated for blood $\beta \mathrm{HB}$ and anesthesia latency as individual data points and as group means [23]. Results were considered significant when $p<0.05$.

\section{Results}

Effects of exogenous ketone supplements on blood $\beta \mathrm{HB}$ and glucose levels and body weight

A significant increase in blood $\beta \mathrm{HB}$ levels was demonstrated after the final (7th) treatment by all exogenous ketone supplements (KE, KS, KSMCT, KEKS and KEMCT; group 2-6), compared to both control (SD; $p<0.01$ for KS; $p<0.001$ for KSMCT; $p<0.0001$ for KE, KEKS and KEMCT) and baseline ( $<0.001$ for KS; $\mathrm{p}<0.0001$ for KE, KSMCT, KEKS and KEMCT) levels (Fig. 1a; Table 1).

After the 7th treatment day, changes in glucose levels and body weight of animals were not detected (Fig. 1b and c; Table 1 and Table 2).

Effect of exogenous ketone supplements on isofluraneinduced anesthesia: delay in the latency to onset of immobility

Treatments by all exogenous ketone supplements (KE, KS, KSMCT, KEKS and KEMCT; group 2-6) caused a significant increase in the number of seconds required before anesthetic induction (the time until immobility), compared to control (SD; $p<0.05$ for KSMCT; $p<0.001$

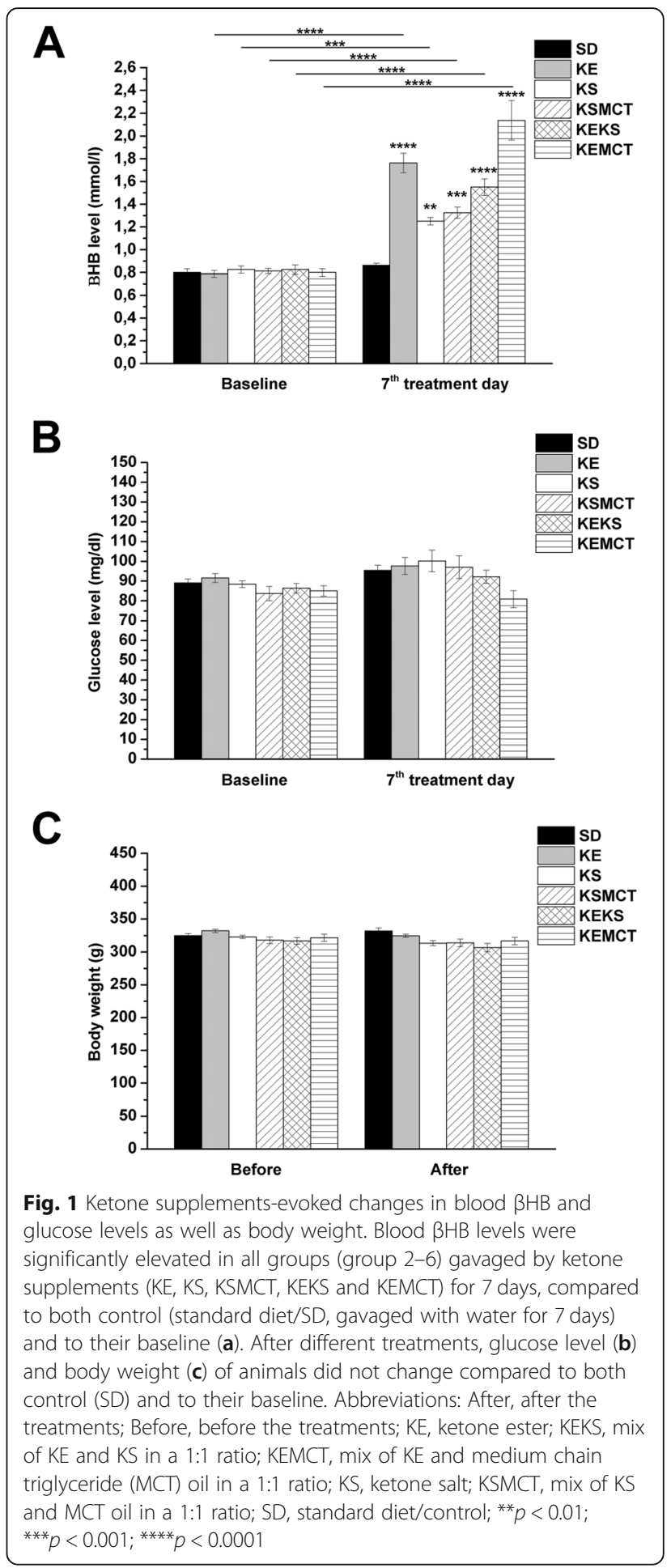

for KS; $p<0.0001$ for KE, KEKS and KEMCT) (Fig. 2a; Table 3) on the 7th day of treatment.

Exogenous ketone supplement-induced delay in isoflurane-generated anesthesia (increase in latency to immobility) positively correlated with blood $\beta \mathrm{HB}$ levels when individual data points $\left(R^{2}=0.2933\right)$ or the group 
Table 1 Effect of ketone supplements on blood $\beta \mathrm{HB}$ and glucose levels on the 7th day of gavage

\begin{tabular}{|c|c|c|c|c|}
\hline \multirow{3}{*}{$\begin{array}{l}\text { Treatments } \\
\text { ( } 2.5 \text { g/kg/day; Fig. 1a) }\end{array}$} & \multicolumn{4}{|l|}{ Blood $\beta$ HB level } \\
\hline & Baseline & \multicolumn{3}{|l|}{ 7th treatment day } \\
\hline & $\begin{array}{l}\text { mmol/l } \\
\text { (mean } \pm \text { S.E.M.) }\end{array}$ & $\begin{array}{l}\text { mmol/l } \\
(\text { mean } \pm \text { S.E.M. })\end{array}$ & $\begin{array}{l}\text { Compared to baseline } \\
\text { (significance level/q-value) }\end{array}$ & $\begin{array}{l}\text { Compared to control } \\
\text { (significance level/q-value) }\end{array}$ \\
\hline SD (control; group 1) & $0.80 \pm 0.037$ & $0.86 \pm 0.018$ & $-/ 0.945$ & - \\
\hline KE (group 2) & $0.79 \pm 0.029$ & $1.76 \pm 0.087$ & $* * * * / 14.550$ & $* * * * / 13.610$ \\
\hline KS (group 3) & $0.83 \pm 0.031$ & $1.25 \pm 0.033$ & $* * * / 6.805$ & $* * / 5.860$ \\
\hline KSMCT (group 4) & $0.81 \pm 0.023$ & $1.33 \pm 0.049$ & $* * * * / 7.939$ & $* * * / 6.994$ \\
\hline KEKS (group 5) & $0.83 \pm 0.041$ & $1.55 \pm 0.073$ & $* * * * / 11.340$ & $* * * * / 10.400$ \\
\hline \multirow[t]{2}{*}{ KEMCT (group 6) } & $0.80 \pm 0.033$ & $2.14 \pm 0.172$ & $* * * * / 20.230$ & $* * * * / 19.280$ \\
\hline & \multicolumn{4}{|c|}{ Blood glucose level } \\
\hline \multirow{2}{*}{$\begin{array}{l}\text { Treatments } \\
\text { (2.5 g/kg/day; Fig. 1b) }\end{array}$} & Baseline & \multicolumn{3}{|l|}{ 7th treatment day } \\
\hline & $\begin{array}{l}\text { mg/dl } \\
\text { (mean } \pm \text { S.E.M.) }\end{array}$ & $\begin{array}{l}\text { mg/dl } \\
\text { (mean } \pm \text { S.E.M.) }\end{array}$ & $\begin{array}{l}\text { Compared to baseline } \\
\text { (significance level/q-value) }\end{array}$ & $\begin{array}{l}\text { Compared to control } \\
\text { (significance level/q-value) }\end{array}$ \\
\hline SD (control; group 1) & $89.00 \pm 1.937$ & $95.38 \pm 2.672$ & $-/ 1.764$ & - \\
\hline KE (group 2) & $91.50 \pm 2.284$ & $97.63 \pm 4.342$ & $-/ 2.386$ & $-/ 0.623$ \\
\hline KS (group 3) & $88.38 \pm 1.772$ & $100.13 \pm 5.482$ & $-/ 3.078$ & $-/ 1.314$ \\
\hline KSMCT (group 4) & $83.63 \pm 3.600$ & $97.00 \pm 5.745$ & $-/ 2.213$ & $-/ 0.449$ \\
\hline KEKS (group 5) & $86.38 \pm 2.398$ & $92.13 \pm 3.388$ & $-/ 0.865$ & $-/ 0.899$ \\
\hline KEMCT (group 6) & $85.00 \pm 2.659$ & $80.88 \pm 4.286$ & $-/ 2.248$ & $-/ 4.011$ \\
\hline
\end{tabular}

Abbreviations: KE, ketone ester; KEKS, mix of KE and KS in a 1:1 ratio; KEMCT, mix of KE and medium chain triglyceride (MCT) oil in a 1:1 ratio; KS, ketone salt; $\mathrm{KSMCT}$, mix of KS and MCT oil in a 1:1 ratio; SD, standard diet/control; ${ }^{* *} p<0.01 ;{ }^{* * *} p<0.001 ;{ }^{* * * *} p<0.0001$

means were considered $\left(R^{2}=0.5553\right)$ (Fig. $2 b$ and $c$, respectively).

\section{Effect of A1R and A2AR inhibition on KEKS-evoked increase in latency to immobility}

Administration of i.p. DPCPX $(0.2 \mathrm{mg} / \mathrm{kg}$; group 7) and $\mathrm{SCH} 58261(0.5 \mathrm{mg} / \mathrm{kg}$; group 8) alone (without KEKS administration) did not cause significant changes in the number of seconds required before isoflurane-induced anesthesia (latency to immobility), compared to control (SD; Fig. 3; Table 3) on the 7th day of gavage. It was demonstrated that i.p. $0.2 \mathrm{mg} / \mathrm{kg}$ DPCPX completely abolished the effect of KEKS on latency to immobility (group 9) (Fig. 3), whereas i.p. $0.5 \mathrm{mg} / \mathrm{kg} \mathrm{SCH} 58261$ (group 10) was ineffective on the KEKS-induced effect (Fig. 3; Table 3). After combined administration of KEKS with SCH 58261 on the 7th day of gavage, latency to immobility significantly increased, compared to control (SD; Fig. 3; Table 3) and both the rate of this increase and its significance level $(p<0.0001)$ was similar to results, which were recorded after gavage of KEKS alone (group 5) (Fig. 3; Table 3).

Table 2 Effect of ketone supplements on body weight

\begin{tabular}{|c|c|c|c|}
\hline \multirow{3}{*}{$\begin{array}{l}\text { Treatments } \\
(2.5 \mathrm{~g} / \mathrm{kg} / \text { day; Fig. 1) }\end{array}$} & \multicolumn{3}{|l|}{ Body weight } \\
\hline & \multirow{2}{*}{$\begin{array}{l}\text { Before the treatments } \\
\text { Gram (mean } \pm \text { S.E.M.) }\end{array}$} & \multicolumn{2}{|l|}{ After the treatments } \\
\hline & & Gram (mean \pm S.E.M.) & $\begin{array}{l}\text { Compared to 'Before the treatments' } \\
\text { (significance level/q-value) }\end{array}$ \\
\hline SD (control, group 1) & $325.0 \pm 3.134$ & $331.8 \pm 4.427$ & $-/ 1.464$ \\
\hline KE (group 2) & $331.9 \pm 2.496$ & $324.9 \pm 2.608$ & $-/ 0.027$ \\
\hline KS (group 3) & $323.1 \pm 2.394$ & $313.5 \pm 3.942$ & $-/ 2.495$ \\
\hline KSMCT (group 4) & $318.0 \pm 5.119$ & $314.0 \pm 5.719$ & $-/ 2.386$ \\
\hline KEKS (group 5) & $316.9 \pm 5.377$ & $306.6 \pm 6.434$ & $-/ 3.986$ \\
\hline KEMCT (group 6) & $321.8 \pm 5.502$ & $316.8 \pm 5.640$ & $-/ 1.790$ \\
\hline
\end{tabular}

Abbreviations: KE, ketone ester; KEKS, mix of KE and KS in a 1:1 ratio; KEMCT, mix of KE and medium chain triglyceride (MCT) oil in a 1:1 ratio; KS, ketone salt; $\mathrm{KSMCT}$, mix of KS and MCT oil in a 1:1 ratio; SD, standard diet/control 


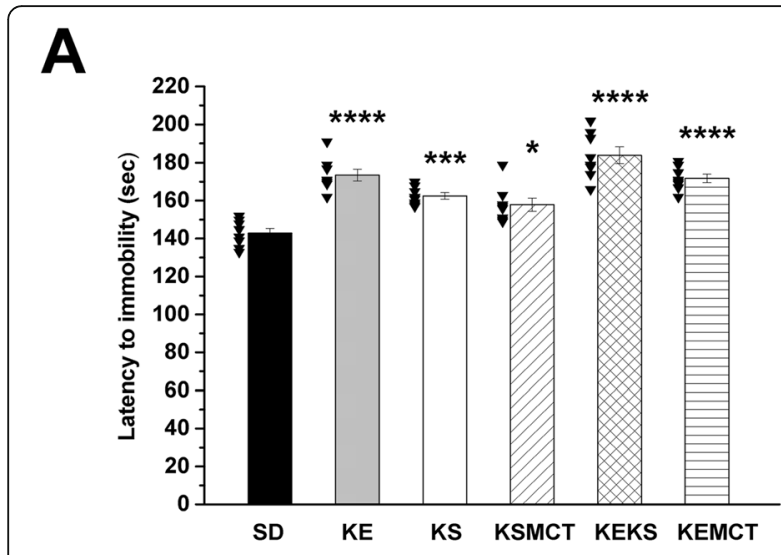

B

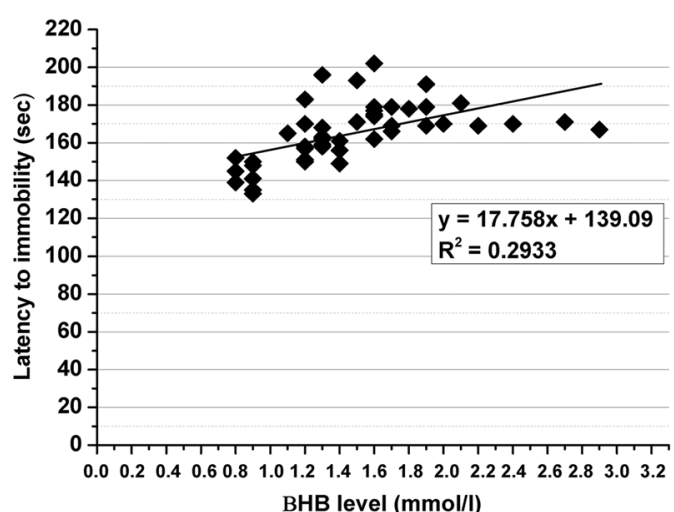

C

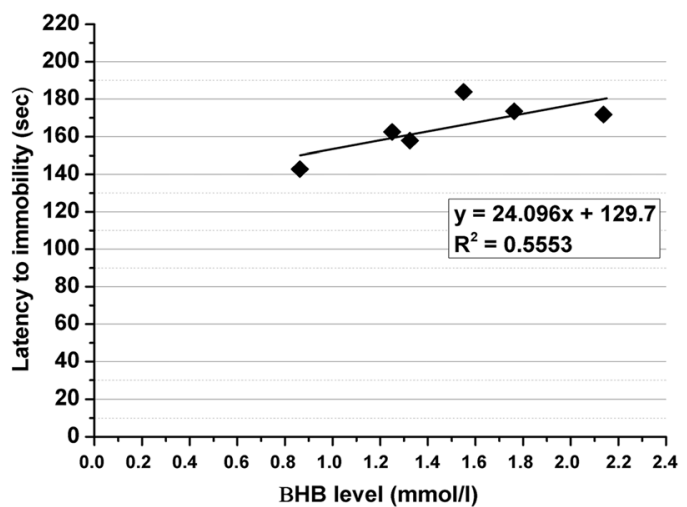

Fig. 2 Effect of ketone supplements on isoflurane-induced anesthesia (latency to immobility). Gavage by exogenous ketone supplements (KE, KS, KSMCT, KEKS and KEMCT; group 2-6) significantly increased the latency to anesthetic induction (the time until immobility), compared to control (SD) on the 7th day of gavage (a: the raw data was plotted as filled black triangles to the left of the columns). There was a positive correlation between latency to immobility and blood $\beta H B$ levels when all data point $\left(\mathbf{b} ; R^{2}=0.2933\right)$ or the group means $\left(\mathbf{c} ; R^{2}=0.5553\right)$ were considered. Abbreviations: KE, ketone ester; KEKS, mix of KE and KS in a 1:1 ratio; KEMCT, mix of KE and medium chain triglyceride (MCT) oil in a 1:1 ratio; $K S$, ketone salt; $K S M C T$, mix of $K S$ and $M C T$ oil in a 1:1 ratio; SD, standard diet/control; ${ }^{*} p<0.05 ;{ }^{* * *} p<0.001 ;{ }^{* * *} p<0.0001$

\section{Discussion}

In this study we demonstrated that inhibition of A1Rs completely abolished the KEKS-evoked delay in isofluraneinduced anesthesia (immobility) in WAG/Rij rats. Moreover, we extended our previous results showing that not only gavage of KE and KS [23], but also KSMCT, KEKS and KEMCT are able to increase both the blood level of $\beta \mathrm{HB}$ (ketosis) and number of seconds required before induction of anesthesia (immobility).

Although isoflurane has been used in patients for nearly 50 years [19], its mechanism of action remains largely unknown. In spite of that both behavioral and physiological differences in functioning of sleep and general anestheticsinduced sleep-like state were demonstrated (e.g., general anesthesia is not able to appear spontaneously), it was suggested that several brain areas, such as cerebral cortex and the hypothalamic nucleus ventrolateral preoptic area may participate in both processes [42-44]. It was hypothesized, that anesthetics, such as isoflurane may induce anesthesia through common endogenous arousal neural circuitry/sleep pathways $[44,45]$.

Administration of exogenous ketone supplements by gavage and subsequent metabolism $[17,46,47]$ increases levels of ketone bodies in the blood stream (nutritional ketosis) [1, 2, 4, 32]. Ketone bodies, such as $\beta \mathrm{HB}$ may enter into the brain through blood brain barrier and modulate different physiological and pathophysiological processes, such as sleep or seizures $[7,8,12]$. As ketosis $(\beta \mathrm{HB})$ increases adenosine level [14] in the brain tissue and adenosine has a role in the sleep generation $[28,29]$, enhanced level of $\beta \mathrm{HB}$ generated by ketone supplements may modulate naturally occurring sleep. Indeed, exogenous ketone supplement-generated ketosis may evoke a decrease in total sleep time through ventrolateral preoptic area $[20,21,44]$. Moreover, it has been demonstrated that level and metabolism of both ketone bodies [7, 18, 48], as well as adenosine and expression of adenosine receptors [49] are regionally different in the brain, which strengthen the modulatory role of ketone bodies and adenosine in processes such as sleep and sleep-like states. Ketosis-evoked increase in extracellular adenosine levels may change neuronal activity in different brain areas $[22,49]$ implicated in sleep/sleep-like effects by its receptors. Increased level of adenosine was demonstrated during waking whereas adenosine concentration decreased during sleep in the brain [50]. Adenosine agonists induced sleep/electroencephalographic slow-wave activity, but adenosine receptor antagonists (e.g., a nonselective antagonist of adenosine receptors caffeine) reversed effects of adenosine on the sleep [51]. Moreover, adenosine accumulates under, for example, sleep deprivation and may have a role in the anesthetic action of isoflurane [28, 44]: theophylline (a non-selective antagonist of adenosine receptors) reversed the cerebral 
Table 3 Effect of ketone supplements, DPCPX, and SCH 58261 alone as well as ketone supplement KEKS in combination with DPCPX or SCH 58261 on latency to immobility on the 7th day of gavage

\begin{tabular}{lll}
\hline & \multicolumn{2}{l}{ Latency to immobility } \\
\cline { 2 - 3 } Treatments (2.5 g/kg/day; Figs. 2a and 3) & Sec (mean \pm S.E.M.) & Compared to control (significance level/q-value) \\
\hline SD (control, group 1) & $142.88 \pm 2.474$ & - \\
KE (group 2) & $173.50 \pm 3.105$ & $* * * / 10.220$ \\
KS (group 3) & $162.50 \pm 1.679$ & $* * / 6.548$ \\
KSMCT (group 4) & $157.88 \pm 3.446$ & $* / 5.005$ \\
KEKS (group 5) & $183.88 \pm 4.299$ & $* * * / 13.680$ \\
KEMCT (group 6) & $171.75 \pm 2.226$ & $-/ 0.765$ \\
DPCPX (group 7) & $146.25 \pm 4.443$ & $-/ 0.283$ \\
SCH 58261 (group 8) & $141.63 \pm 4.935$ & $-/ 1.177$ \\
KEKS + DPCPX (group 9) & $138.13 \pm 4.202$ & $* * * * 12.290$ \\
KEKS + SCH 58261 (group 10) & $187.13 \pm 5.531$ &
\end{tabular}

Abbreviations: DPCPX (DP), 1,3-dipropyl-8-cyclopentylxanthine (a specific adenosine A1 receptor/A1R antagonist); KE, ketone ester; KEKS, mix of KE and KS in a 1:1 ratio; KEMCT, mix of KE and medium chain triglyceride (MCT) oil in a 1:1 ratio; KS, ketone salt; KSMCT, mix of KS and MCT oil in a 1:1 ratio; SCH (SC), SCH 58261, 7(2-phenylethyl)-5-amino-2-(2-furyl)-pyrazolo-[4,3-e]-1,2,4-triazolo[1,5-c] pyrimidine (a selective adenosine A2A receptor/A2AR antagonist); SD, standard diet/control; ${ }^{*} p<0.05 ;{ }^{* * *} p<0.001 ;{ }^{* * * *} p<0.0001$

effects of isoflurane in dogs (e.g., EEG has been changed from a sleep pattern to an awake pattern) [30] and caffeine accelerated emergence from isoflurane-evoked anesthesia in humans [52]. Moreover, enhanced activity of A1Rs (e.g., by an A1R agonist N-sulfophenyl adenosine) may cause increase in anesthesia recovery time [53]

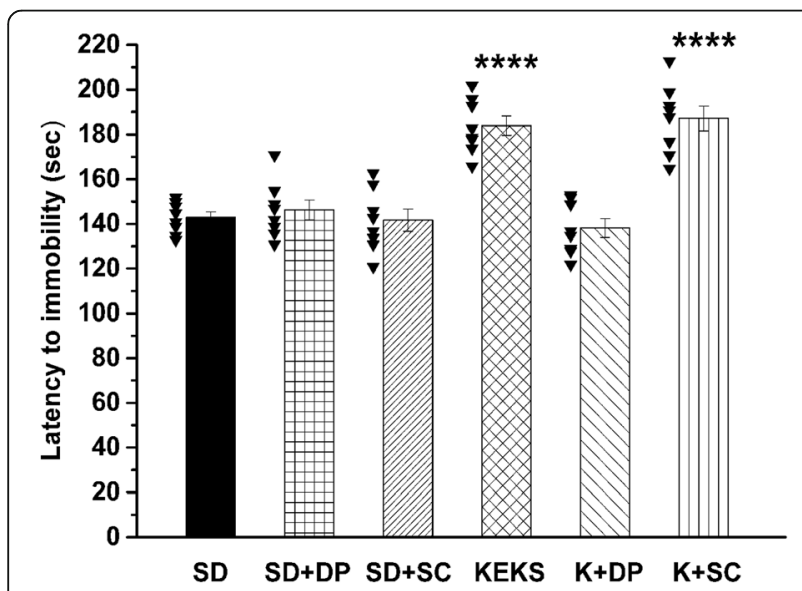

Fig. $\mathbf{3}$ Influence of A1R antagonist DPCPX and A2AR antagonist SCH 58261 on KEKS-generated changes in isoflurane-evoked anesthesia (latency to immobility). Administration of DPCPX (i.p. $0.2 \mathrm{mg} / \mathrm{kg}$; $\mathrm{SD}+\mathrm{DP} ;$ group 7) and SCH 58261 (i.p. $0.5 \mathrm{mg} / \mathrm{kg} ; \mathrm{SD}+\mathrm{SC}$; group 8) alone did not modulate the latency to immobility, compared to control (SD; the raw data was plotted as filled black triangles to the left of the columns). Combined administration of DPCPX (i.p. $0.2 \mathrm{mg} /$ $\mathrm{kg}$ ) with KEKS (K+DP; group 9) completely abolished the effect of KEKS on latency to immobility, whereas SCH 58261 (i.p. $0.5 \mathrm{mg} / \mathrm{kg}$ ) was ineffective on the KEKS-induced influence (K+SC; group 10); Abbreviations: DP (DPCPX), 1,3-dipropyl-8-cyclopentylxanthine (a specific adenosine $\mathrm{A} 1$ receptor/A1R antagonist); KEKS, mix of KE and KS in a 1:1 ratio; SC (SCH 58261), 7-(2-phenylethyl)-5-amino-2-(2-furyl)pyrazolo-[4,3-e]-1,2,4-triazolo[1,5-c] pyrimidine (a selective adenosine A2A receptor/A2AR antagonist); SD, standard diet/control; ${ }^{* * *} p<0.0001$ and isoflurane may activate A1Rs [54]. It has been demonstrated that receptors of adenosine, such as inhibitory A1Rs and excitatory A2ARs are expressed brain areas implicated in the generation of sleep and sleep-like effects, such as ventrolateral/lateral preoptic area and basal forebrain [29]. Thus, adenosine may be a link between the anesthetic actions of isoflurane and sleep regulation as an endogenous sleep factor.

It was also demonstrated that inhibition or disinhibition by A1Rs (e.g., in wake-promoting neurons of basal forebrain or sleep-active neurons of ventrolateral preoptic area, respectively) may induce sleep $[29,55,56]$. Nevertheless, A1Rs may also promote wakefulness by inhibition of sleep-active neurons in lateral preoptic area [57] and in ventrolateral preoptic area [58]. Consequently, we can hypothesize that adenosinergic system may modulate the influence of exogenous ketone supplements, such as KEKS, on the onset of isofluraneinduced anesthesia (immobility) by inhibition of sleep active neurons (possibly by ketosis and, as a consequence, through increase in adenosine level as well as its A1Rs) [14, 23], which processes lead to delay in the anesthetic effects of isoflurane. Indeed, although the A1R antagonist DPCPX alone did not change the isoflurane-generated anesthetic effect (immobility), combined administration of DPCPX with KEKS completely abolished the KEKS-evoked increase in latency to immobility under isoflurane anesthesia (Fig. 3). Moreover, adenosine receptors may also modulate anesthesia recovery time $[52,53]$. Thus, it is possible that exogenous ketone supplements not only delay the onset of isoflurane-induced anesthesia (immobility) [23] (Fig. 2a and 3), but also modulate the time required for recovery from anesthesia. However, further studies are needed to 
determine the exact effect and mechanism(s) of action of exogenous ketone supplements (ketosis) on isofluranegenerated anesthetic effects.

As it was demonstrated, not only A1Rs but also A2ARs are implicated in sleep generation, and A2ARs are considered more important in sleep regulation [29]: increased activity of A2ARs, for example, in ventrolateral/lateral preoptic area may induce sleep through sleep-active/promoting neurons $[57,59]$. It has been demonstrated that A1Rs are abundantly expressed in the brain whereas A2AR expression is week in most of brain areas such as ventrolateral preoptic area $[29,49,60]$. Thus, as it was demonstrated, effects of adenosine on both sleep [29, 5558 ] and processes of anesthesia may be brain region- and receptor-dependent. In addition, our knowledge relating to the exact role of adenosinergic system in modulation of both isoflurane-evoked anesthesia and connections between brain areas implicated in processes of anesthesia is far from complete. Consequently, it is possible that A1Rs are predominant whereas A2ARs are secondary (if any) in adenosine-evoked influences on anesthesia at least at this level of isoflurane-generated anesthesia (loss of consciousness without movement: immobility) in WAG/Rij rats. Indeed, our results suggest that A2ARs have no effect on isoflurane-generated anesthesia (immobility): neither isoflurane-induced anesthesia (latency to immobility) nor the effect of exogenous ketone supplement KEKS on isoflurane-induced anesthesia (latency to immobility) were modulated by the A2AR antagonist SCH 58261 (Fig. 3). Nevertheless, it cannot be excluded that this physiologically effective dose of A2AR antagonist SCH 58261 (0.5 $\mathrm{mg} / \mathrm{kg}$ ) may not have been adequate to investigate its influence on isoflurane-generated light phase of anesthesia (loss of consciousness without movement, immobility), but may modulate the later/deeper phase(s) of isofluraneevoked anesthesia. However, more studies are needed to explain the exact role of adenosine and its receptors in isoflurane-induced anesthesia.

It has been demonstrated that gavage of exogenous ketone supplements, such as KSMCT for 7 days not only increases the number of seconds required before isoflurane-induced anesthetic induction (the time until immobility) (Fig. 2a) [23], but also generates decrease in both anxiety level on elevated plus maze [36] and absence epileptic activity [32] in WAG/Rij rats. These effects may be in correlation with enhanced level of $\beta \mathrm{HB}$ $[23,32,36]$ (Fig. 2b and c). Moreover, it was showed that inhibition of A1Rs may abolish the anti-anesthetic (Fig. 3), antiepileptic [32] and anxiolytic [36] effects of exogenous ketone supplements, suggesting that adenosinergic system may modulate the ketone supplements (ketosis) induced influences in the CNS. Indeed, it was proposed that adenosinergic system (e.g., through A1Rs) has a role in the modulation of sleep and sleep-like effects [28-30], different types of epilepsies [61-63] and anxiety [64-66]. However, new studies are needed to reveal the likely (at least partly) common mechanism(s), as well as interactions of adenosine receptors and adenosine receptor-evoked changes (e.g., in ion channels, signal transduction, metabolic processes) in different brain areas involved in sleep/sleep-like effects, epilepsy and anxiety, by which ketone supplements could exert its above mentioned influences.

One limitation of our study is that we used the WAG/Rij rat strain exclusively to investigate the effect of ketone supplementation on isoflurane-induced anesthesia. In addition, during this study we narrowed our focus on the influence of ketone supplement-evoked effects to the adenosinergic system. Nevertheless, this WAG/Rij rat strain is extensively used for investigation of different drugs on CNS diseases [1, 67$71]$, and the present study further supports our previous experiments [23] on the role of the adenosinergic system. It has been suggested that the ketosis/3HB-evoked increase in adenosine levels [14] can modulate influence of ketone supplements not only on different CNS diseases $[8,32,36]$, but also sleep and sleep-like effects [20, 21, 28-30] via adenosinergic system (likely through A1Rs). Consequently, we propose that the adenosinergic system may be one of main neurotransmitter systems by which ketone supplements can exert their influence on isoflurane-induced anesthesia. However, to get comprehensive view on influence of ketone supplements on isoflurane-evoked anesthesia more studies are needed on other animal strains and humans, on changes not only in adenosinergic, but also other neuromodulatory/ neurotransmitter systems (such as cholinergic, dopaminergic, and GABAergic system), and on other phases of anesthesia/ emergence from anesthesia [24, 53, 72] by administration of different/higher doses and types of ketone supplements. Further studies are also needed to reveal exact effects of different doses of drugs were used, such as DPCPX and SCH 58261, on isoflurane-generated anesthesia by administration of distinct methods (e.g., not only i.p., but also microinjections/microdialysis to specific brain areas, such as basal forebrain, as well as intravenous administration) $[57,58,73]$.

\section{Conclusion}

The present study strengthened the putative clinical and surgical relevance of ketone supplements-evoked influences on sleep and sleep-like effects suggested by our previous results: exogenous ketone supplements may increase the resistance to the isoflurane-induced anesthetic influence by delaying the onset of anesthesia (immobility). Thus, monitoring of blood ketone levels in humans undergoing isoflurane and (theoretically) other inhalational anesthesia may be important and helpful for the anesthesiologists. Moreover, inhibitory effect of DPCPX on KEKS-evoked delay in isoflurane-generated anesthesia (immobility) suggests that the adenosinergic system, likely via $\mathrm{A}_{1} \mathrm{Rs}$, may modulate the exogenous ketone 
supplements-evoked anti-anesthetic influence. However, further studies are needed to reveal the exact mechanism(s) of action of exogenous ketone supplements (ketosis) on isoflurane-generated anesthesia not only in animals, but also in human subjects because ketone supplements used in normal and pathological conditions may modify the time needed for anesthesia.

\begin{abstract}
Abbreviations
$A_{1} R$ : Adenosine $A_{1}$ receptor; A2AR: Adenosine A2A receptor; CNS: Central nervous system; DMSO: Dimethyl sulfoxide; DPCPX: 1,3-dipropyl-8cyclopentylxanthine; i.p.: intraperitoneal; $K_{\text {ATP }}$ channels: ATP-sensitive potassium channels; KE (ketone ester): 1,3 butanediol-acetoacetate diester; KEKS: (mix of KE and KS); KEMCT: (mix of KE and MCT oil); KS: ketone salt; KSMCT: (mix of KS and MCT oil); MCT: medium chain triglyceride; $\mathrm{SCH}$ 58261: 7-(2-phenylethyl)-5-amino-2-(2-furyl)-pyrazolo-[4,3-e]-1,2,4-triazolo[1,5c]pyrimidine; SD: Standard rodent chow diet; WAG/Rij: Wistar Albino Glaxo/ Rijswijk; $\beta H B$ : beta-hydroxybutyrate
\end{abstract}

\section{Acknowledgements}

Not Applicable.

\section{Authors' contributions}

All authors read and approved the final manuscript. ZK: design of experiments, acquisition, analysis, and interpretation of data, writing manuscript, BB: acquisition of data, DPD: revising manuscript, CA: analysis of data, writing manuscript.

\section{Funding}

This work was supported by the National Development Agency of Hungary (under Grant No. TIOP-1.3.1.-07/2-2F-2009-2008), OTKA K124558 Research Grant (to Zsolt Kovács), ONR Grant N000141310062 (to Dominic P. D'Agostino). The funding body had no influence on the design of the study, collection and analysis of data, interpretation of results and writing the manuscript.

\section{Availability of data and materials}

The data used and/or analyzed during the current study available from the corresponding author on reasonable request.

\section{Ethics approval and consent to participate}

Animal treatments were carried out according to Hungarian Act of Animal Care and Experimentation (1998, XXVIII, section 243), European Communities Council Directive 24 November 1986 (86/609/EEC) and EU Directive 2010/63/ EU to use and treat animals in experimental laboratories. The experimental design was approved by the Animal Care and Experimentation Committee of the Eötvös Loránd University (Savaria University Centre) and National Scientific Ethical Committee on Animal Experimentation (Hungary) under license number VA/ÉBNTF02/85-8/2016.

\section{Consent for publication}

Not Applicable.

\section{Competing interests}

International Patent \# PCT/US2014/031237, University of South Florida for DPD: "Compositions and Methods for Producing Elevated and Sustained Ketosis". Non provisional patent No. 210112-9018-US02 for AC and DPD. Technology Title: "Methods of Increasing Latency of Anesthetic Induction Using Ketone Supplementation". AC and DPD are co-owners of the company Ketone Technologies LLC, providing scientific consulting and public speaking engagements about ketogenic therapies. The company obtained an option agreement from the University of South Florida on the non-provisional patent no. 62/310,302 "Methods of increasing latency of anesthetic induction using ketone supplementation." These interests have been reviewed and managed by the University in accordance with its Institutional and Individual Conflict of Interest policies. All authors declare that there are no additional conflicts of interest.

\section{Author details}

'Savaria Department of Biology, ELTE Eötvös Loránd University, Savaria University Centre, Szombathely, Hungary. ${ }^{2}$ Institute of Biology, University of
Pécs, Pécs, Hungary. ${ }^{3}$ Department of Molecular Pharmacology and Physiology, Laboratory of Metabolic Medicine, Morsani College of Medicine University of South Florida, Tampa, FL, USA. ${ }^{4}$ Institute for Human and Machine Cognition, Ocala, FL, USA. ${ }^{5}$ Department of Psychology, Hyperbaric Neuroscience Research Laboratory, University of South Florida, 4202 E. Fowler Ave, PCD 3127, Tampa, FL 33620, USA.

Received: 3 October 2019 Accepted: 16 January 2020

Published online: 30 January 2020

\section{References}

1. Ari C, Kovács Z, Juhasz G, Murdun C, Goldhagen CR, Koutnik AM, Poff AM, Kesl SL, D'Agostino D. Exogenous ketone supplements reduce anxietyrelated behavior in Sprague-Dawley and Wistar albino Glaxo/Rijswijk rats. Front Mol Neurosci. 2016:9:137.

2. D'Agostino DP, Pilla R, Held HE, Landon CS, Puchowicz M, Brunengraber $H$, Ari C, Arnold P, Dean JB. Therapeutic ketosis with ketone ester delays central nervous system oxygen toxicity seizures in rats. Am J Physiol Regul Integr Comp Physiol. 2013;304(10):829-36

3. Hashim SA, Vanltallie TB. Ketone body therapy: from the ketogenic diet to the oral administration of ketone ester. J Lipid Res. 2014;55(9):1818-26.

4. Kesl SL, Poff AM, Ward NP, Fiorelli TN, Ari C, Van Putten AJ, Sherwood JW, Arnold P, D'Agostino DP. Effects of exogenous ketone supplementation on blood ketone, glucose, triglyceride, and lipoprotein levels in SpragueDawley rats. Nutr Metab. (Lond.) 2016;13:9.

5. Kovács Z, D'Agostino DP, Diamond DM, Ari C. Exogenous ketone supplementation decreased the lipopolysaccharide-induced increase in absence epileptic activity in Wistar albino Glaxo Rijswijk rats. Front Mol Neurosci. 2019;12:45

6. Stubbs BJ, Cox PJ, Evans RD, Santer P, Miller JJ, Faull OK, Magor-Elliott S, Hiyama S, Stirling M, Clarke K. On the metabolism of exogenous ketones in humans. Front Physiol. 2017;8:848.

7. Achanta $L B$, Rae CD. $\beta$-Hydroxybutyrate in the brain: one molecule, multiple mechanisms. Neurochem Res. 2017;42(1):35-49.

8. Kovács Z, D'Agostino DP, Diamond D, Kindy MS, Rogers C, Ari C. Therapeutic potential of exogenous ketone supplement induced ketosis in the treatment of psychiatric disorders: review of current literature. Front Psychiatry. 2019;10:363.

9. Sato K, Kashiwaya Y, Keon C, Tsuchiya N, King MT, Radda GK, Chance B, Clarke K, Veech RL. Insulin, ketone bodies, and mitochondrial energy transduction. FASEB J. 1995;9(8):651-8.

10. Juge N, Gray JA, Omote H, Miyaji T, Inoue T, Hara C, Uneyama H, Edwards RH, Nicoll RA, Moriyama Y. Metabolic control of vesicular glutamate transport and release. Neuron. 2010;68(1):99-112.

11. Simeone TA, Simeone KA, Rho JM. Ketone bodies as anti-seizure agents. Neurochem Res. 2017:42(7):2011-8.

12. Newman JC, Verdin E. Ketone bodies as signaling metabolites. Trends Endocrinol Metab. 2014:25(1):42-52

13. McNally MA, Hartman AL. Ketone bodies in epilepsy. J Neurochem. 2012; 121(1):28-35.

14. Sharma AK, Rani E, Waheed A, Rajput SK. Pharmacoresistant epilepsy: a current update on non-conventional pharmacological and nonpharmacological interventions. J Epilepsy Res. 2015;5(1):1-8.

15. Youm YH, Nguyen KY, Grant RW, Goldberg EL, Bodogai M, Kim D, D'Agostino D, Planavsky N, Lupfer C, Kanneganti TD, Kang S, Horvath TL, Fahmy TM, Crawford PA, Biragyn A, Alnemri E, Dixit VD. The ketone metabolite $\beta$-hydroxybutyrate blocks NLRP3 inflammasome-mediated inflammatory disease. Nat Med. 2015;21(3):263-9.

16. Newport MT, Vanltallie TB, Kashiwaya Y, King MT, Veech RL. A new way to produce hyperketonemia: use of ketone ester in a case of Alzheimer's disease. Alzheimers Dement. 2015;11(1):99-103.

17. Clarke K, Tchabanenko K, Pawlosky R, Carter E, Todd King M, Musa-Veloso K, Ho M, Roberts A, Robertson J, Vanitallie TB, Veech RL. Kinetics, safety and tolerability of (R)-3-hydroxybutyl (R)-3-hydroxybutyrate in healthy adult subjects. Regul Toxicol Pharmacol. 2012;63(3):401-8.

18. Allen CN. Circadian rhythms, diet, and neuronal excitability. Epilepsia. 2008; 49(Suppl 8):124-6.

19. Constantinides C, Murphy K. Molecular and integrative physiological effects of isoflurane anesthesia: the paradigm of cardiovascular studies in rodents using magnetic resonance imaging. Front Cardiovasc Med. 2016;3:23. 
20. Hallböök T, Ji S, Maudsley S, Martin B. The effects of the ketogenic diet on behavior and cognition. Epilepsy Res. 2012;100(3):304-9.

21. Hallböök T, Lundgren J, Rosén I. Ketogenic diet improves sleep quality in children with therapy-resistant epilepsy. Epilepsia. 2007:48(1):59-65.

22. Masino SA, Kawamura M, Wasser CD, Pomeroy LT, Ruskin DN. Adenosine, ketogenic diet and epilepsy: the emerging therapeutic relationship between metabolism and brain activity. Curr Neuropharmacol. 2009;7(3):257-68.

23. Ari C, Kovács Z, Murdun C, Koutnik AP, Goldhagen CR, Rogers C, Diamond D, D'Agostino DP. Nutritional ketosis delays the onset of isoflurane induced anesthesia. BMC Anesthesiol. 2018;18(1):85.

24. Hanusch C, Hoeger S, Beck GC. Anaesthesia of small rodents during magnetic resonance imaging. Methods. 2007;43(1):68-78.

25. Joksovic PM, Weiergräber M, Lee W, Struck H, Schneider T, Todorovic SM. Isoflurane-sensitive presynaptic R-type calcium channels contribute to inhibitory synaptic transmission in the rat thalamus. J Neurosci. 2009;29(5): 1434-45.

26. Kofke WA, Hawkins RA, Davis DW, Biebuyck JF. Comparison of the effects of volatile anesthetics on brain glucose metabolism in rats. Anesthesiology. 1987;66(6):810-3.

27. Rogawski MA, Löscher W, Rho JM. Mechanisms of action of antiseizure drugs and the ketogenic diet. Cold Spring Harb Perspect Med. 2016;6(5), pii: a022780.

28. Porkka-Heiskanen T, Strecker RE, Thakkar M, Bjorkum AA, Greene RW McCarley RW. Adenosine: a mediator of the sleep-inducing effects of prolonged wakefulness. Science. 1997;276(5316):1265-8.

29. Huang $Z \mathrm{~L}$, Urade $\mathrm{Y}$, Hayaishi $\mathrm{O}$. The role of adenosine in the regulation of sleep. Curr Top Med Chem. 2011;11(8):1047-57.

30. Roald OK, Forsman M, Steen PA. Partial reversal of the cerebral effects of isoflurane in the dog by theophylline. Acta Anaesthesiol Scand. 1990;34(7): 548-51.

31. Coenen AM, Van Luijtelaar EL. Genetic animal models for absence epilepsy: a review of the WAG/Rij strain of rats. Behav Genet. 2003;33(6):635-55.

32. Kovács Z, D'Agostino DP, Dobolyi A, Ari C. Adenosine A1 receptor antagonism abolished the anti-seizure effects of exogenous ketone supplementation in Wistar albino Glaxo Rijswijk rats. Front Mol Neurosci. 2017;10:235

33. Lee $E$, Kang HC, Kim HD. Ketogenic diet for children with epilepsy: a practical meal plan in a hospital. Clin Nutr Res. 2016;5(1):60-3.

34. Rho JM. How does the ketogenic diet induce anti-seizure effects? Neurosci Lett. 2017:637:4-10.

35. Yudkoff M, Daikhin Y, Melø TM, Nissim I, Sonnewald U, Nissim I. The ketogenic diet and brain metabolism of amino acids: relationship to the anticonvulsant effect. Annu Rev Nutr. 2007;27:415-30.

36. Kovács Z, D'Agostino DP, Ari C. Anxiolytic effect of exogenous ketone supplementation is abolished by adenosine A1 receptor inhibition in Wistar albino Glaxo/Rijswijk rats. Front Behav Neurosci. 2018;12:29.

37. Dubroqua S, Yee BK, Singer P. Sensorimotor gating is disrupted by acute but not chronic systemic exposure to caffeine in mice. Psychopharmacology. 2014;231(21):4087-98.

38. Fontinha BM, Delgado-García JM, Madroñal N, Ribeiro JA, Sebastião AM, Gruart $\mathrm{A}$. Adenosine a(2A) receptor modulation of hippocampal CA3-CA1 synapse plasticity during associative learning in behaving mice. Neuropsychopharmacology. 2009;34(7):1865-74

39. Kovács Z, Czurkó A, Kékesi KA, Juhász G. The effect of intraperitoneally administered dimethyl sulfoxide on absence-like epileptic activity of freely moving WAG/Rij rats. J Neurosci Methods. 2011;197(1):133-6.

40. Cavas M, Beltrán D, Navarro JF. Behavioural effects of dimethyl sulfoxide (DMSO): changes in sleep architecture in rats. Toxicol Lett. 2005;157(3):221-32.

41. Wang L, Holland L, Fong R, Khokhar S, Fox AP, Xie Z. A pilot study showing that repeated exposure to stress produces alterations in subsequent responses to anesthetics in rats. PLoS One. 2019;14(3):e0214093.

42. Moore JT, Chen J, Han B, Meng QC, Veasey SC, Beck SG, Kelz MB. Direct activation of sleep-promoting VLPO neurons by volatile anesthetics contributes to anesthetic hypnosis. Curr Biol. 2012;22(21):2008-16.

43. Saper CB, Chou TC, Scammell TE. The sleep switch: hypothalamic control of sleep and wakefulness. Trends Neurosci. 2001;24(12):726-31.

44. Tung A, Mendelson WB. Anesthesia and sleep. Sleep Med Rev. 2004;8(3): 213-25

45. Nelson LE, Guo TZ, Lu J, Saper CB, Franks NP, Maze M. The sedative component of anesthesia is mediated by GABA(a) receptors in an endogenous sleep pathway. Nat Neurosci. 2002;5(10):979-84.
46. Schönfeld P, Wojtczak L. Short- and medium-chain fatty acids in energy metabolism: the cellular perspective. J Lipid Res. 2016;57(6):943-54.

47. Tate RL, Mehlman MA, Tobin RB. Metabolic fate of 1,3-butanediol in the rat: conversion to -hydroxybutyrate. J Nutr. 1971;101(12):1719-26.

48. Hawkins RA, Biebuyck JF. Ketone bodies are selectively used by individual brain regions. Science. 1979;205(4403):325-7.

49. Kovács Z, Juhász G, Palkovits M, Dobolyi A, Kékesi KA. Area, age and gender dependence of the nucleoside system in the brain: a review of current literature. Curr Top Med Chem. 2011;11(8):1012-33.

50. Porkka-Heiskanen T, Strecker RE, McCarley RW. Brain site-specificity of extracellular adenosine concentration changes during sleep deprivation and spontaneous sleep: an in vivo microdialysis study. Neuroscience. 2000;99(3): 507-17.

51. Schwierin B, Borbély AA, Tobler I. Effects of N6-cyclopentyladenosine and caffeine on sleep regulation in the rat. Eur J Pharmacol. 1996;300(3):163-71.

52. Fong R, Wang L, Zacny JP, Khokhar S, Apfelbaum JL, Fox AP, Xie Z. Caffeine accelerates emergence from isoflurane anesthesia in humans: a randomized, double-blind, crossover study. Anesthesiology. 2018;129(5):912-20.

53. Gettys GC, Liu F, Kimlin E, Baghdoyan HA, Lydic R. Adenosine a(1) receptors in mouse pontine reticular formation depress breathing, increase anesthesia recovery time, and decrease acetylcholine release. Anesthesiology. 2013; 118(2):327-36.

54. Tas PW, Eisemann C, Roewer N. The volatile anesthetic isoflurane suppresses spontaneous calcium oscillations in vitro in rat hippocampal neurons by activation of adenosine A1 receptors. Neurosci Lett. 2003;338(3):229-32.

55. Blanco-Centurion C, Xu M, Murillo-Rodriguez E, Gerashchenko D, Shiromani AM, Salin-Pascual RJ, Hof PR, Shiromani PJ. Adenosine and sleep homeostasis in the basal forebrain. J Neurosci. 2006;26(31):8092-100.

56. Morairty S, Rainnie D, McCarley R, Greene R. Disinhibition of ventrolateral preoptic area sleep-active neurons by adenosine: a new mechanism for sleep promotion. Neuroscience. 2004;123(2):451-7.

57. Methippara MM, Kumar S, Alam MN, Szymusiak R, McGinty D. Effects on sleep of microdialysis of adenosine A1 and A2a receptor analogs into the lateral preoptic area of rats. Am J Physiol Regul Integr Comp Physiol. 2005; 289(6):1715-23.

58. Zhang J, Yin D, Wu F, Zhang G, Jiang C, Li Z, Wang L, Wang K. Microinjection of adenosine into the hypothalamic ventrolateral preoptic area enhances wakefulness via the $\mathrm{A} 1$ receptor in rats. Neurochem Res. 2013;38(8):1616-23.

59. Scammell TE, Gerashchenko DY, Mochizuki T, McCarthy MT, Estabrooke IV, Sears CA, Saper CB, Urade Y, Hayaishi O. An adenosine A2a agonist increases sleep and induces Fos in ventrolateral preoptic neurons. Neuroscience. 2001;107(4):653-63.

60. Fredholm BB, IJzerman AP, Jacobson KA, Klotz KN, Linden J. International Union of Pharmacology. XXV. Nomenclature and classification of adenosine receptors. Pharmacol Rev. 2001;53(4):527-52.

61. D'Alimonte I, D'Auro M, Citraro R, Biagioni F, Jiang S, Nargi E, Buccella S, Di lorio P, Giuliani P, Ballerini P, Caciagli F, Russo E, De Sarro G, Ciccarelli R. Altered distribution and function of $\mathrm{A} 2 \mathrm{~A}$ adenosine receptors in the brain of WAG/Rij rats with genetic absence epilepsy, before and after appearance of the disease. Eur J Neurosci. 2009;30(6):1023-35.

62. Masino SA, Li T, Theofilas P, Sandau US, Ruskin DN, Fredholm BB, Geiger JD, Aronica $\mathrm{E}$, Boison D. A ketogenic diet suppresses seizures in mice through adenosine A1 receptors. J Clin Invest. 2011;121(7):2679-83.

63. Kovács Z, Kékesi KA, Juhász G, Dobolyi A. The antiepileptic potential of nucleosides. Curr Med Chem. 2014;21(6):788-821.

64. Klein E, Zohar J, Geraci MF, Murphy DL, Uhde TW. Anxiogenic effects of mCPP in patients with panic disorder: comparison to caffeine's anxiogenic effects. Biol Psychiatry. 1991;30(10):973-84.

65. Johansson B, Halldner L, Dunwiddie TV, Masino SA, Poelchen W, GiménezLlort L, Escorihuela RM, Fernández-Teruel A, Wiesenfeld-Hallin Z, Xu XJ, Hårdemark A, Betsholtz C, Herlenius E, Fredholm BB. Hyperalgesia, anxiety, and decreased hypoxic neuroprotection in mice lacking the adenosine A1 receptor. Proc Natl Acad Sci U S A. 2001;98(16):9407-12.

66. Giménez-Llort L, Fernández-Teruel A, Escorihuela RM, Fredholm BB, Tobeña $A$, Pekny $M$, Johansson B. Mice lacking the adenosine $A 1$ receptor are anxious and aggressive, but are normal learners with reduced muscle strength and survival rate. Eur J Neurosci. 2002;16(3):547-50.

67. Sarkisova K, van Luijtelaar G. The WAG/Rij strain: a genetic animal model of absence epilepsy with comorbidity of depression. Prog NeuroPsychopharmacol Biol Psychiatry. 2011;35(4):854-76. 
68. Kovács Z, Kékesi KA, Szilágyi N, Abrahám I, Székács D, Király N, Papp E, Császár I, Szego E, Barabás K, Péterfy H, Erdei A, Bártfai T, Juhász G.

Facilitation of spike-wave discharge activity by lipopolysaccharides in Wistar albino Glaxo/Rijswijk rats. Neuroscience. 2006;140(2):731-42.

69. Kovács Z, Czurkó A, Kékesi KA, Juhász G. Neonatal tricyclic antidepressant clomipramine treatment reduces the spike-wave discharge activity of the adult WAG/Rij rat. Brain Res Bull. 2012;89(3-4):102-7.

70. Kovács Z, Kékesi KA, Dobolyi Á, Lakatos R, Juhász G. Absence epileptic activity changing effects of non-adenosine nucleoside inosine, guanosine and uridine in Wistar albino Glaxo Rijswijk rats. Neuroscience. 2015;300:593-608.

71. Citraro R, lannone M, Leo A, De Caro C, Nesci V, Tallarico M, Abdalla K Palma E, Arturi F, De Sarro G, Constanti A, Russo E. Evaluation of the effects of liraglutide on the development of epilepsy and behavioural alterations in two animal models of epileptogenesis. Brain Res Bull. 2019;153:133-42.

72. Kelz MB, García PS, Mashour GA, Solt K. Escape from oblivion: neural mechanisms of emergence from general anesthesia. Anesth Analg. 2019; 128(4):726-36.

73. Tung A, Herrera S, Szafran MJ, Kasza K, Mendelson WB. Effect of sleep deprivation on righting reflex in the rat is partially reversed by administration of adenosine $\mathrm{A} 1$ and $\mathrm{A} 2$ receptor antagonists. Anesthesiology. 2005;102(6):1158-64.

\section{Publisher's Note}

Springer Nature remains neutral with regard to jurisdictional claims in published maps and institutional affiliations.

Ready to submit your research? Choose BMC and benefit from:

- fast, convenient online submission

- thorough peer review by experienced researchers in your field

- rapid publication on acceptance

- support for research data, including large and complex data types

- gold Open Access which fosters wider collaboration and increased citations

- maximum visibility for your research: over $100 \mathrm{M}$ website views per year

At BMC, research is always in progress.

Learn more biomedcentral.com/submissions 